\title{
Outcomes beyond hospital discharge in infants and children with viral meningitis: a systematic review
}

Jessica A. Hudson, MRCPCH1; Jonathan Broad, MRCPCH2; Natalie G. Martin DPhil2, 3; Manish Sadarangani, DPhil2,4; Dominic F. Kelly, PhD2; Andrew J. Pollard, FMedSci2; Seilesh Kadambari, PhD2

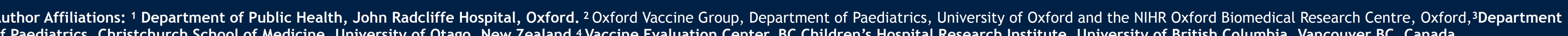

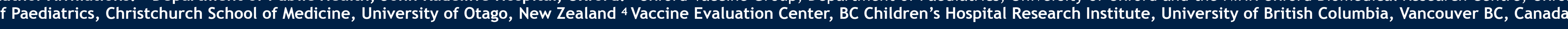

\section{BACKGROUND}

Viral meningitis is common however the longterm management is inconsistent. In a recent British study only $38-46 \%$ patients received any follow-up during the 12 months after hospital discharge.

\section{METHODS}

Medline, Embase, clinicaltrials.gov, Cochrane review were searched for studies from 1990 to December 2017.

- Search terms used were 'viral meningitis' OR specific viruses AND meningitis AND terms for outcomes such as 'hearing' AND terms for child or neonate.

\begin{tabular}{lc}
\multicolumn{1}{c}{ Inclusion criteria } & Exclusion criteria \\
-Human studies & •Encephalitis or \\
- Children 0-16 years & meningoencephalitis \\
- Confirmed viral meningitis & ${ }^{-C a s e ~ r e p o r t s ~ a n d ~}$ \\
- Defined outcome beyond & conference abstracts \\
hospital discharge &
\end{tabular}

Viral meningitis defined by a clinical diagnosis of meningitis and either CSF positive for a specific virus on culture or PCR, or CSF lymphocytosis with virus identified from any site by PCR, culture or antibody titres.

Results: Study flowchart (PRISMA)

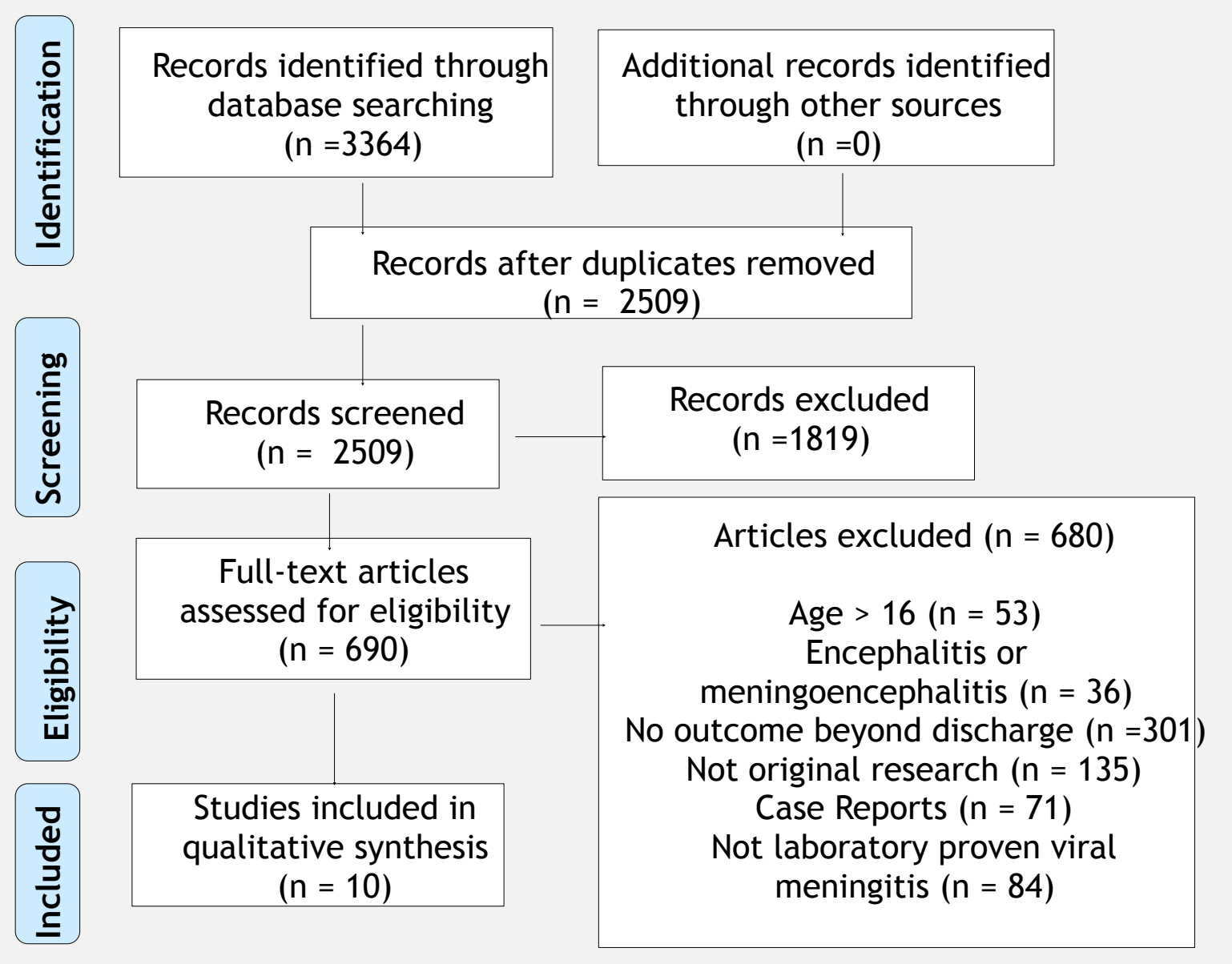

Results: Outcomes post hospital discharge following viral meningitis for all studies meeting inclusion criteria

Bakreta

Baker et 1996

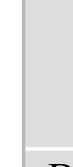

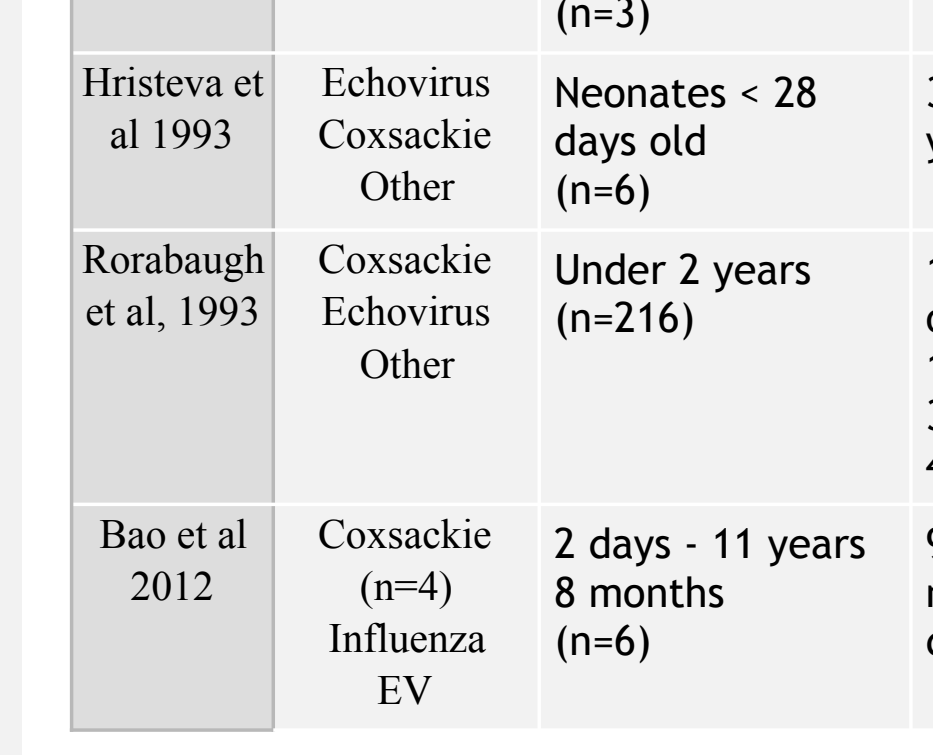

\section{References}

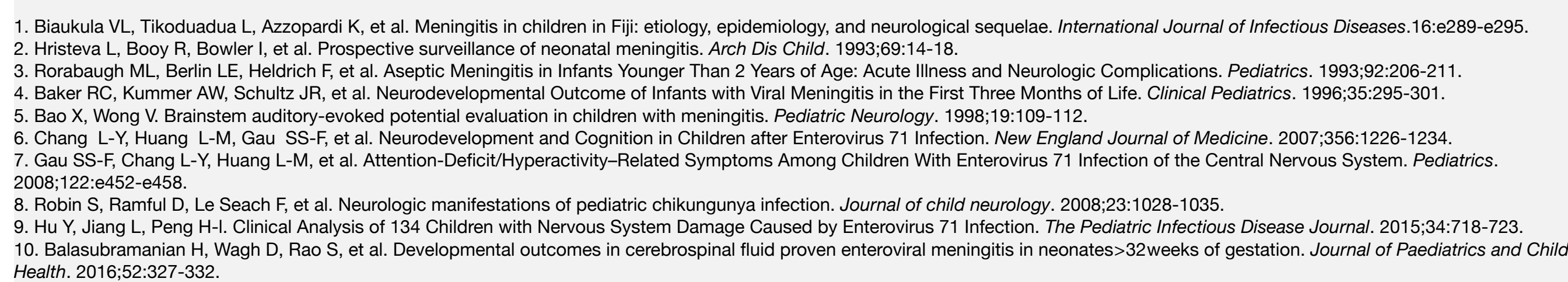

Conclusions

- Generally favourable outcomes

with limited long term sequelae

- Some effects seen on:

language, hearing and

behaviour

- Long-term neurodevelopment

studies are warranted 